\title{
Conteúdos do Ensino: Compreensão do Real ou o Avesso da Realidade?
}

Pesquisadora: Eloisa Guimarães

Instituição: Universidade Federal do Rio de Janeiro (UFRJ)

Fonte Financiadora: Instituto Nacional de Estudos e Pesquisas Educacionais (INEP)

Os sistemas de ensino voltados últimos anos, por alunos cada vez para a educação de jovens e adultos mais jovens, reduzindo-se a - Ensino Regular Noturno (RN) e participação dos adultos nesses Ensino Supletivo -, no Rio de programas'. Em pesquisa realizada Janeiro, vêm sendo procurados, nos entre 1989 e 1990, em duas escolas

\footnotetext{
' Em levantamento realizado em 1986, em escolas do ensino supletivo no município do Rio (cf Liberato e Nogueira, 1986), essa tendência já se manifestava de forma clara: segundo esse levantamento, $70,6 \%$ dos alunos que frequentavam as escolas investigadas tinha entre 14 e 20 anos; deste grupo, 53,7\% tinha entre 14 e 16 anos, e 46,3\% estava na faixa de idade compreendida entre 17 e 20 anos.
} 
de $I^{0}$ grau regular noturno no município do Rio $^{2}$, essa tendência era bastante evidente: de 287 alunos matriculados entre a $5^{\mathrm{a}}$ e a $8^{\mathrm{a}}$ série em uma das escolas - Escola Ipê $\hat{e}^{3}$, a maior concentração recaía na faixa de 16 e 17 anos: 43,6\%; se ampliarmos esta faixa, incluindo as idades de 15 e 18 anos, chega-se a um total de $72 \%$, aproximadamente, reduzindo-se a $14,6 \%$ o percentual de jovens entre 19 e 20 anos e a apenas $7,3 \%$ para aqules com mais de 20 anos. Na outra escola Escola das Acácias -, essa situação é ainda mais acentuada: $51 \%$ dos alunos têm entre 16 e 17 anos, enquanto entre 15 e 18 anos estão $80,3 \%$; na faixa de 19 e 20 anos recaem $12,7 \%$, e os que têm mais de 20 anos representam apenas $1,5 \%$ do total.

Nesse contexto de uma população estudantil constituída por uma parcela expressiva de alunos muito jovens, em grande parte transferidos do diurno - não, necessariamente porque tivessem que trabalhar, mas sobretudo por defasagem de idade ou por motivos diversos da própria escola, como falta de vagas, indisciplina etc. - é que se desenvolveu a pesquisa em questão, e é com essa perspectiva que se pode compreender melhor os dados obtidos. O objetivo inicial da pesquisa era o de, a partir de pesquisa de campo com alunos do $\mathrm{RN}$, de $\mathrm{I}^{\mathrm{o}}$ grau, analisar os conteúdos curriculares, tomando-se como base as representações dos alunos sobre a escola, sobre os conhecimentos e habilidades por ela transmitidos e sobre a adequação desses conteúdos à sua realidade, inclusive ao mundo do trabalho; visava a uma busca de conteúdos curriculares apropriados às características da população investigada. A imagem que a equipe de pesquisa tinha do RN, formulada a partir da literatura existente, era a do lugar onde os alunos trabalhadores iriam em busca do saber elaborado, ao

\footnotetext{
${ }^{2}$ A instalação do RN no município do Rio de Janeiro era recente, tendo ocorrido entre 1987 e 1988.

' Os nomes das escolas são fictícios. A Escola Ipê contava, à epóca, com 331 alunos matriculados da 5" à 8" série. Os dados aqui trabalhados são constantes das fichas de matrículas de 291 alunos, em 1989. Faltavam as fichas de 40 alunos que, no entanto, constavam das pautas dos professores. As fichas de quatro alunos não continham informações quanto à idade, sendo desprezadas para o cálculo apresentado.
} 
qual não tiveram acesso no tempo devido. Entretanto, a pesquisa mostrou que a procura do noturno não estava, necessariamente, condicionada à colocação prévia dos estudantes no mundo do trabalho, verifícando-se, em várias situações, a relação inversa: muitos deles afirmavam procurar trabalho porque haviam sido obrigados a estudar à noite. Por outro lado, como se verá adiante, poucos valorizavam a escola como espaço de aquisição de conhecimentos. Outros aspectos, ainda, da realidade dos estudantes, como a presença, em uma das escolas, de jovens ligados ao tráfico de drogas, levaram a uma revisão dos propósitos acima declarados, buscando incluir esses aspectos, sem no entanto perder de vista os objetivos iniciais.

Os procedimentos previstos para o trabalho de campo - entrevistas não-diretivas ${ }^{4}$ a serem realizadas individualmente com os alunos, e observação do cotidiano das escolas - também foram parcialmente reformulados. As entrevistas individuais realizadas no início, em diferentes situações, mostraram-se, progressivamente, pouco produtivas do ponto de vista da temática em estudo. Os alunos mostravamse reticentes, pouco disponíveis para a abordagem dos temas propostos, resultando essas entrevistas em depoimentos pobres em informação e repetitivos. Na fala dos entrevistados, percebia-se a construção de um discurso em que se dizia aquilo que se supunha que o entrevistador - ou a escola esperava ouvir. Em vista disso, as entrevistas individuais deram lugar a entrevistas em pequenos grupos, cada grupo com número reduzido de estudantes. Esse segundo momento possibilitou o acesso ao cotidiano daqueles jovens e as suas formulações sobre a escola, o trabalho, os conteúdos escolares, o problema da droga e do crime organizado. Embora o trabalho de campo estivesse organizado de modo a se concentrar predominantemente sobre os alunos, marginalmente foram feitas entrevistas com

\footnotetext{
4 Sobre as caracteristicas e processo de realização da entrevista não-diretiva, ver Thiollent, 1982.
} 
professores e diretores das duas escolas. Também de forma complementar, foram realizadas entrevistas com professores e diretores de outras escolas públicas na tentativa não só de buscar uma confirmação para a realidade de violência encontrada em uma das escolas, mas uma explicação para essa situação.

Os alunos da Escola Ipê eram predominantemente do sexo masculino $(73,7 \%)$, originando-se em grande parte de áreas próximas ao estabelecimento; uma parcela menor vinha de bairros mais distantes ou mesmo de outros municípios da periferia do Grande Rio, mas tendo no centro da cidade seu local de trabalho. Essa escola está localizada no pólo de maior concentração comercial e de serviços do município, em uma região de grande confluência de transportes coletivos.

$\mathrm{Na}$ Escola das Acácias, a distribuição entre os sexos era quase equivalente (52\% de homens e $48 \%$ de mulheres), e os alunos provenientes, em sua grande maioria, dos morros vizinhos, com um número reduzido de pessoas de bairros mais distantes. A escola situa-se na zona norte, em área central da Tijuca, caracterizada por residências de famílias de classe média e por uma rede comercial expressiva. Tem à sua volta alguns dos morros mais problemáticos do Rio de Janeiro, do ponto de vista da ocupação pelo tráfico, como Borel, Formiga, Coroa, Macaco, Turano, entre outros, onde se vê, de forma permanente, a disputa de grupos em conflito pelo controle do tráfico esse é um dado relevante para o entendimento da realidade encontrada, como se verá adiante. Espacialmente, a escola não se insere nesses territórios, apresentando certo distanciamento físico em relação a eles.

Permeando o discurso dos vários alunos entrevistados, a escola aparecia como forma de "ter um futuro melhor", de "melhorar de vida", entre outras formulações semelhantes. Essas declarações adquiriam maior especificidade entre aqueles estudantes que trabalhavam, variando conforme o tipo de atividade desenvolvida.

Em relação à questão do trabalho, a situação das duas escolas era diferenciada. A Escola Ipê, por 
sua própria situação geográfica, recebia um número maior de alunos trabalhadores, que trabalhavam no centro da cidade - dividindo-se entre atividades formais e informais - e frequentavam a escola à noite: aproximadamente $70 \%$ dos alunos entrevistados. Muitos eram camelos, vendiam alimentos na Central do Brasil, trabalhavam como contínuos ou "boys" em escritórios das proximidades, em gráficas etc. Entre as mulheres, a maior parte do grupo era formada por balconistas, vendedoras e empregadas domésticas. Entre os que se apresentavam como trabalhadores, parte não tinha ocupação fixa, mas fazia "bicos" em determinados períodos do ano, quando a atividade comercial se intensificava. Nesses períodos, esses estudantes abandonavam a escola, retornando com a volta do comércio aos padrões normais, ou mesmo no ano seguinte. Este era um dos fatores com que os professores pretendiam explicar o alto índice de evasão - havia casos de turma com 27 alunos matriculados e apenas oito a frequentando. Um outro fator apresentado era o de que parte dos alunos trabalhadores buscavam na escola apenas o comprovante exigido pelas empresas para mantelos no emprego, deixando-a logo que o obtinham.

Para alguns dos alunos que trabalhavam, a escola era apresentada como o meio para conseguir outra profissão. Esse era o caso, principalmente, da empregada doméstica, cujo sonho era trabalhar no comércio ou como operária, mesmo ganhando menos, mas tendo a certeza de sua independência e autonomia. Os que estavam vinculados formalmente ao setor de serviços, trabalhando em firmas comerciais, em bancos, alguns em empresas multinacionais, afirmavam ver na escola uma forma de melhorar seu desempenho no trabalho e, principalmente, de ascender na hierarquia ocupacional. Para os que estavam no setor informal a escolaridade era, muitas vezes, o canal para obter uma ocupação regulamentada.

Na Escola Acácia, o número de alunos inseridos no mundo do trabalho era bem reduzido. Os poucos que trabalhavam eram vendedores de lojas, entregadores de supermercados, padeiros, enfer- 
meiras, empregadas domésticas. Um número pequeno ficava em casa cuidando dos irmãos ${ }^{5}$. Parte dos alunos dessa escola fazia um "trabalho" ligado ao tráfico, como "avião", "vapor" etc.

Um fato que se destacou durante o trabalho nessa escola foi a presença ativa, tanto entre os alunos trabalhadores quanto entre os nãotrabalhadores, de subgrupos ligados aos diferentes grupos de dividem as áreas de influência no tráfico de drogas. Embora não tenha sido possível quantificar o número de alunos envolvidos com a droga, pelos depoimentos colhidos dentro e fora de escola, pode-se afirmar que, naquele momento, dentro dessa escola, reproduzia-se a briga das quadrilhas de traficantes dos morros vizinhos. As paredes, repletas de pichações, representavam a briga de diferentes grupos pelo domínio dos espaços da escola ${ }^{6}$. Muitos alunos entravam armados. Em uma "batida" feita pela direção, várias armas foram apre- endidas. Esse tipo de violência é característico dessa escola e, mais de uma vez, ouvimos referências a ameaças de alunos a professores e à própria direção. Situações dessa natureza levaram a direção, mais de uma vez, a buscar proteção junto aos chefes dos morros. Se essa era uma especificidade dessa escola em relação à outra instituição investigada na pesquisa —, fica claro, atualmente, que tal situação caracteriza um conjunto expressivo de escolas públicas no Rio de Janeiro, atingindo de forma particular aquelas localizadas nas proximidades de morros ocupados pelo tráfico.

A Escola Acácia vivia, em 1989, um clima permanente de insegurança e medo. Os alunos nos pátios, em pequenos grupos, cochichando, enquanto em outras ocasiões eram vistos correndo nos andares e o coordenador preocupado em estabelecer a ordem. Tudo indica que estivesse havendo, nessa escola, um deslocamento da

\footnotetext{
${ }^{1}$ Sobre a relação do escolar com trabalhos dessa natureza e suas representações, ver Dauster, 1992

* Em outra pesquisa sobre as relações ente violência e escola, realizada, recentemente, a natureza desses grupos aparece com mais clareza: txata-se, nesse caso, das gangues ou "galeras", organizadas por ruas, morros ou bairros, com frequência associadas às quadrilhas de traficantes
} 
autoridade, transferindo-se de seu interior para os espaços do morro, ou seja, para fora dela, ao mesmo tempo que, internamente, ameaças de estudantes ligados às gangues a professores e diretores subvertiam a hierarquia ${ }^{7}$.

Entre as características comuns às duas escolas, algumas situações são relevantes. Ao abandono da atividade escolar pelos alunos, é necessário associar o fato de que, em ambas, os que permaneciam frequentavam muito a escola mas pouco as aulas, permanecendo no pátio ou na entrada da escola graças a esse movimento é que foi possível realizar grande parte das entrevistas com pequenos grupos. Para muitos a escola é o lugar do encontro social, conforme declarações de vários alunos, de buscar um certificado etc. Para isso, a frequência às aulas não tem muita importância. O número de reprovações, entre eles, é assustador.

Ainda nessa perspectiva, quando se falava do conteúdo dos programas e dos professores, boa parte dos alunos mostrava forte desinteresse. Não só não os valorizavam, mas quase nunca se lembravam do que estavam estudando e mostravam pouco interesse em relação ao tema. O que se valorizava, com frequência, não era o conteúdo programático, mas a empatia com os professores, a dificuldade ou facilidade da disciplina etc: "O francês é legal porque a professora é ótima, animada", "Matemática é difícil". Poucos eram os estudantes que viam nos conteúdos abordados pela escola uma relação com suas vidas e com o trabalho. Destes, vale transcrever os seguintes depoimentos: segundo uma menina de mais de 14 anos, "...eu agora falo de cabeça alta"; ou um rapaz de mais de 20 anos, que trabalhava com "boy" em uma empresa multinacional: "...a gente chega em um lugar e vai se expressar com uma pessoa e fala uma coisa errada e a pessoa diz: 'esse cara aí deve ser um

\footnotetext{
${ }^{7}$ As questões referentes à violência na escola foram pouco trabalhadas neste texto, por já estarem descritas, de forma detalhada, no artigo "Colidiano Escolar e Violência", de Guimarães c Paula, em Zaluar, 1992. Sobre a questão da violência entre jovens urbanos, ver os demais textos do mesmo livro e também o artigo de Zaluar, 1990.
} 
burrão, esse cara não sabe nem falar direito, o português dele é péssimo'".

Está claro que os alunos não vêem nos conteúdos escolares uma possibilidade real de mudança em suas vidas, de modo que projetam no futuro uma utilidade e um sentido para os estudos. Segundo Dubet (1991, p.25), "...os estudos adquirem, senão um sentido pelo menos uma utilidade se o autor inscreve seu trabalho e seus esforços em um percurso, na realização de objetivos mais ou menos claros, Para trabalhar hoje, o aluno deve projetar no futuro uma imagem dele mesmo, de seu estatuto, de sua posição e de seu métier. Desta maneira os estudos são percebidos como mais ou menos úteis, adaptados, adequados à realização de um projeto".

Essa idéia de um projeto, e de uma subordinação a ele, dos estudos realizados, é pouco perceptível entre grande parte dos alunos entrevistados, que parecem incorporar a escolaridade apenas como dado formal, como estratégia de cumprimento de exigências específicas do mercado de trabalho e da sociedade atual, na medida que, segundo suas declarações, "hoje, até para ser gari, para lavar o chão do supermercado, eles exigem o $1^{\circ}$ grau".

A pesquisa realizada - embora de natureza exploratória - coloca em questão, pelo menos em parte, alguns dos pressupostos e princípios definidos pela literatura e pelas políticas oficiais brasileiras para $o$ ensino noturno. Tudo indica que se esteja diante de um quadro novo em relação à educação dos jovens nos grandes centros urbanos brasileiros, diante do qual se faz necessário diversificar os temas de investigação hoje priorizados pelos pesquisadores e pelos órgãos financiadores, de modo a incluir outros aspectos relevantes, como as novas formas de percepção e os padrões culturais emergentes entre os jovens nas sociedades atuais (a esse respeito são relevantes as contribuições de Willis, 1990 e 1991), além dos problemas específicos inerentes às escolas das grandes cidades: a violência, a questão sexual etc. Embora não tenha sido tratada acima, a questão referente à sexualidade aparece como um dos 
grandes problemas, entre os professores, não só por uma certa erotização entre os alunos, e pela presença do sexo no interior do espaço escolar, mas pelo nível de desinformação entre eles, sobretudo entre as meninas.

Uma revisão das políticas educacionais, de modo a incorporar alguns desses temas, parece ser necessária, inclusive no que diz respeito à formação dos professores. Uma das frases que mais se ouvia por parte destes, no transcorrer da pesquisa, era "não fomos preparados pra isso", numa referência à questão do sexo e da violência.

Referências Bibliográficas

CARVALHO, Célia P. de. Ensino noturno: realidade e ilusão. São Paulo: Cortez: Autores Associados, 1984.

DAUSTER, Tânia. Uma infância de curta duração: trabalho e escola.
Cadernos de Pesquisa, São Paulo, n.82, p.31-36, ago. 1992.

DUBET, Francois. Leslycéens. Paris: Seuil, 1991.

LIBERATO, Edna, NOGUEIRA, Norma P.F. Reflexões sobre o atual aluno do supletivo. Rio de Janeiro: Secretaria Estadual de Educação, Coordenação do Ensino Supletivo, 1986. mimeo.

THIOLLENT, Michel. Critica metodológica, investigação social e enquete operaria. São Paulo: Polis, 1982.

WILLIS, Paul. Common culture. Bristol. Open University Press, 1990.

- Aprendendo a ser trabalhador: escola, resistência e reprodução social. Porto Alegre: Artes Medicas, 1991.
ZALUAR, Alba. Teleguiados e chefes: juventude e crime. Religião $e$ Sociedade, v.l5, n.l,p.54-8l, 1990.

(Org). Violência e educação. São Paulo: Livros do Tatu: Cortez, 1992. 